\title{
Self, a serviço de quem?
}

\section{Self, at whose service?}

As múltiplas faces do self, de Walter Trinca (2016) retrata o self e suas implicações na vida psíquica como uma importante instância reguladora do desenvolvimento emocional da pessoa. Por tratar-se de um receptáculo que possui mobilidade, plasticidade, características variadas e peculiares, abriga e movimenta inúmeras forças advindas da mente, do organismo e do mundo externo, sofre influências destas e torna-se um campo de conflitos. O self guarda estreita relação com o 'ser interior' que é considerado o núcleo de existência do indivíduo. $\mathrm{O}$ autor dá ênfase à influência benéfica que o 'ser interior' (força vital) exerce sobre o self, promovendo o desenvolvimento emocional, a integração e o bem-estar da pessoa, e a 'má influência' da

${ }^{* 1}$ Psicóloga clínica (Santo André, SP, Br). 
pulsão de morte, sob a forma de 'constelação do inimigo interno' (Trinca, 2007, 2011), provocando embates e conflitos que podem culminar com a 'ação da fragilidade ou a presença da sensorialidade' no self. Ou seja, as ações do self dependerão da maior ou menor influência do 'ser interior'.

Vale a pena enfatizar que a fragilidade do self decorre do predomínio da pulsão de morte, voltada para o indivíduo, que provoca angústias intensas pelo 'medo do terror de passagem à inexistência', e pode resultar desde o enfraquecimento até o esvaziamento do self. Já a sensorialidade corresponde a uma ocupação do self' que 'tende a se constituir como um modo de ser, de representar o mundo e de estar no mundo' (p. 27). Esses e outros aspectos são abordados com muita propriedade, oferecendo ao leitor uma compreensão profunda levando-o a reflexões acerca da dinâmica do self e outros elementos a ele relacionados, como também as implicações dos possíveis arranjos nele estabelecidos, para o bem e para o mal, que determinam as condições emocionais de cada pessoa em diferentes momentos da sua vida. $\mathrm{O}$ autor dedica um capítulo sobre algumas concepções de self, destacando a que embasa o teor desse livro. Discorre sobre a natureza, a estrutura, a dinâmica do self e sua importância para os processos psíquicos. Retoma o conceito de 'ser interior', a interlocução deste com o self e a influência do instinto de morte. Destaca a necessidade do contato da pessoa com o seu próprio ser. Esclarece que a condição de a pessoa desenvolver patologias está relacionada ao distanciamento de contato, enquanto a expansão da consciência decorre de contatos crescentes com o 'ser interior'. Propõe um modelo de organização e estruturação do self no âmbito da psicanálise compreensiva, no qual os fatores psicológicos fundamentais se evidenciam na clínica psicanalítica desde que observados numa abordagem de conjunto, a partir das manifestações do self.

Trinca esclarece que o livro em tela complementa suas ideias sobre o self e o 'ser interior', descritas em duas obras anteriores: $O$ ser interior na psicanálise: fundamentos, modelos e processos (2007) e Psicanálise compreensiva: uma concepção de conjunto (2011). As concepções sobre a constituição e o funcionamento do self descritas nesse livro foram respaldadas por sua ampla prática clínica e seus conhecimentos teóricos. Embora o autor tenha abordado as funções do self e sua interlocução com o ser interior nas outras obras citadas, nesta, ao dar destaque ao self, como uma engrenagem fundamental dentre os determinantes psíquicos, convida o leitor a aprofundar seus conhecimentos e observar o resultado de algumas das possíveis interações que ocorrem nesse campo de conflitos na prática clínica. 


\section{RESENHAS BIBLIOGRÁFICAS}

Destaco do capítulo intitulado "As derivações do mundo humano", as conjeturas do autor ao transpor conhecimentos da psicanálise para a compreensão de fenômenos sociais. Refiro-me às possibilidades de o self, dado à qualidade e à natureza do que nele se instalam, tornar-se uma força coletiva, produto da interação e projeção de muitos selfs individuais que favorecem a criação de 'instrumentos e ideologias de destruição em massa, guerras e extermínios' (p. 73). As correlações estabelecidas entre o self projetado e a manifestação da desumanização, que se faz presente na própria vida e no ambiente, dão uma dimensão da importância e das consequências dos direcionamentos tomados pelo self projetado quando o self se encontra envolvido por um grande distanciamento de contato, preenchido pela sensorialidade, pela ação da constelação do inimigo interno e outros fatores.

O autor aborda, também, como identificar a manifestação da libertação e da prisão da mente (cap. 11). De um lado, a libertação se apresenta em um self não sensorial, originada pela influência do 'ser interior', permitindo 'uma apreensão do mundo real feita em sintonia com os sentidos e significados que estão contidos nos relacionamentos' (p. 93). De outro, a prisão promove o estreitamento mental como consequência do afastamento de si próprio, comprometendo 'a percepção, a cognição, o pensamento e o sentimento' e daí decorrem os prejuízos à vida e ao viver. Retoma a necessidade de manter o self sob a influência do 'ser interior', para que aquele mantenha a unicidade e a coesão, resultando na mobilidade psíquica da pessoa.

Assim, esse livro, além de retratar um panorama dinâmico das funções do self e das possíveis interações que esse mantém com o 'ser interior' e com as forças pulsionais, especialmente as provenientes da pulsão de morte, é útil ao leitor por possibilitar uma reflexão acerca das manifestações dessas interações na prática clínica e, com isso, proporcionar à pessoa atendida o gerenciamento de sua vida alicerçada em seus aspectos genuínos de existência. Outra razão para a leitura do livro é a forma como o autor aborda o conteúdo, transitando da psicanálise à filosofia e à sociologia proporcionando, ao mesmo tempo, um sentido poético e científico.

Citação/Citation: Martão, M. I. S. (2017, dezembro). Self, a serviço de quem? Resenha do livro As múltiplas faces do self. Revista Latinoamericana de Psicopatologia Fundamental, 20(4), 811-814. http://dx.doi.org/10.1590/1415-4714.2017v20n4p811.14.

Editores do artigo/Editors: Profa. Dra. Sonia Leite 
Recebido/Received: 19.8.2017 / 8.19.2017 Aceito/Accepted: 12.10.2017 / 10.12.2017

Copyright: (C) 2009 Associação Universitária de Pesquisa em Psicopatologia Fundamental/ University Association for Research in Fundamental Psychopathology. Este é um artigo de livre acesso, que permite uso irrestrito, distribuição e reprodução em qualquer meio, desde que o autor e a fonte sejam citados / This is an open-access article, which permits unrestricted use, distribution, and reproduction in any medium, provided the original authors and sources are credited.

\section{Maria Izilda Soares Martao}

Psicóloga clínica; Mestre e Doutora em Psicologia Clínica pela Universidade de São Paulo - USP (São Paulo, SP, Br)

Rua Rui Barbosa, 333/92 - Boa Vista

09190-370 Santo André, SP, Brasil

e-mail: soaizi@hotmail.com

This is an open-access article, which permits unrestricted use, distribution, the original authors and sources are credited. 